\title{
“Estágio de pós-graduação" em Serviço Social no sociojurídico: aproximações preliminares
}

\author{
"Postgraduate Internship" in Social Work \\ in sociojuridical: preliminar approaches
}

\author{
Silvia Tejadas ${ }^{a}$ \\ (D) https://orcid.org/0000-0002-6667-699X \\ Maria Liduína de Oliveira e Silva ${ }^{b}$ \\ (D) https://orcid.org/0000-0002-7904-4836 \\ Rodrigo José Teixeirac \\ (D) https://orcid.org/0000-0002-2993-5294
}

Resumo: 0 artigo tem por objetivo analisar a forma de trabalho precarizado que se escamoteia por "estágio de pós-graduação" na área Sociojurídica. Situa-se o debate no bojo da contrarreforma administrativa, desencadeada após o golpe de 2016, e dos influxos da precarização hoje. Argumenta-se a partir da análise de alguns editais de contratação, denunciando suas armadilhas e riscos para a formação, o trabalho e a garantia de direitos. Conclui-se apontando algumas possibilidades de resistência.

Palavras-chaves: Estágio de Pós-graduação. Sociojurídico. Formação e Trabalho Profissional.

\begin{abstract}
The article aims to analyze the form of precarious work that is concealed by "postgraduate internship" in the Sociojuridical area. The debate is located in the midst of the administrative counter-reform triggered after the 2016 coup and the inflow of precariousness today. It argues based on the analysis of some hiring notices denouncing their pitfalls and dangers for work and the guarantee of rights. We conclude by pointing out some possibilities of resistance.
\end{abstract}

Keywords: Postgraduate Internship. Sociojuridical. Formation and Professional Work.

aMinistério Público do Estado do Rio Grande do Sul/RS, Brasil.

bUniversidade Federal de São Paulo (Unifesp) — campus Baixada Santista, Santos/SP, Brasil.

cUniversidade Federal Fluminense (UFF) — campus Rio das Ostras, Rio das Ostras/RJ, Brasil.

Recebido: 1/9/2021 - Aprovado: 14/9/2021 


\title{
Introdução
}

\begin{abstract}
A dinâmica societária brasileira e os projetos em disputa, na quadra da história posterior ao Golpe de 2016 e contemporâneos ao capitalismo rentista, têm implicado a aceleração dos processos de desconstituição das bases do Estado brasileiro, em especial no tocante ao tamanho e às finalidades deste. Tal realidade apresenta reflexos no conjunto dos espaços sócio-ocupacionais dos assistentes sociais, mesmo que com particularidades.
\end{abstract}

Nesse contexto, as instituições do Sistema de Justiça não escapam às lógicas da contrarreforma administrativa que sinaliza para a precarização do conjunto do serviço público. $O$ presente artigo tece, de modo preliminar, uma aproximação com o tema do "estágio de pós-graduação" em Serviço Social no Ministério Público e no Poder Judiciário, situando esse tema emergente no contexto das reformas do Estado, bem como no âmbito da formação em pós-graduação de assistentes sociais.

Para tanto, o artigo situa a inserção do Serviço Social no Ministério Público e no Poder Judiciário e principais atribuições. Ao mesmo tempo, traz à luz os movimentos de tais instituições no que diz respeito à regulamentação do "estágio de pós-graduação" no contexto da Reforma Administrativa proposta pelo governo Bolsonaro.

Na sequência, são contextualizadas a pós-graduação no ensino superior, as normativas vigentes sobre o estágio, bem como análises introdutórias sobre o tema do "estágio de pós-graduação", no tocante à formação superior.

\section{1. "Estágio de pós-graduação" em instituições do Sociojurídico: uma forma de precarização do trabalho?}

O Serviço Social brasileiro tem feito um esforço ainda inconcluso quanto à compreensão do denominado "Sociojurídico", havendo estudiosas da área profissional que têm construído um conjunto de aproximações 
teórico-práticas, destacando-se Borgianni (2013) e Fávero (2018). Em documento do conjunto CFESS/CRESS de 2014 há referência de que o termo começou a ser utilizado no início dos anos 2000, a partir de eventos realizados pelas referidas entidades, e em publicação da revista Serviço Social \& Sociedade, n. 67 (2001), da Cortez Editora. A área Sociojurídica é longeva na atuação da profissão, considerando sua origem, e tem, ao longo do tempo, em especial a partir da Constituição Federal de 1988 e das legislações infraconstitucionais decorrentes, se expandido para instituições diversas que conformam um entendimento alargado acerca da sua composição. A esse propósito, Borgianni (2013, p. 424, grifos nossos) conceitua:

[...] assim, em termos sintéticos e simples, pode-se dizer que o trabalho do assistente social na área sociojurídica é aquele que se desenvolve não só no interior das instituições estatais que formam o sistema de justiça (Tribunais de Justiça, Ministério Público e Defensorias), o aparato estatal militar e de segurança pública, bem como o Ministério de Justiça e as Secretarias de Justiça dos estados, mas também aquele que se desenvolve nas interfaces com os entes que formam o Sistema de Garantias de Direitos (cf. Conanda, 2006) que, por força das demandas às quais têm que dar respostas, confrontam-se em algum momento de suas ações com a necessidade de resolver um conflito de interesses (individuais ou coletivos) lançando mão da impositividade do Estado, ou seja, recorrendo ao universo jurídico.

Como pode ser observado, o rol de instituições que, grosso modo, perpassa o universo denominado comumente pela categoria profissional como sociojurídico é vasto e heterogêneo, dadas suas idiossincrasias relativas ao ponto específico que ocupam no Sistema de Garantia de Direitos, de Proteção ou de Justiça. Por isso, para fins deste artigo, será feito um recorte direcionado a duas dessas instituições, o Poder Judiciário e o Ministério Público, visto a realidade aqui discutida apresentar-se a elas adstrita.

Desse modo, será feita breve descrição do desenvolvimento da atuação profissional no Poder Judiciário e no Ministério Público, para fins de situar o objeto da discussão. A atuação do Serviço Social no Poder 
Judiciário data provavelmente da década de 1940, revestida de grande importância, visto o Judiciário compor um dos poderes da República do Brasil. Trata-se de instituição do Sistema de Justiça organizada a partir de diversos ramos, nas esferas estadual e federal, em diferentes instâncias, a qual goza de autonomia institucional, administrativa e financeira. Pela sua posição no Sistema de Justiça, caracteriza-se pela inércia, ou seja, age quando provocado, no âmbito do processo.

A atuação de assistente social no Poder Judiciário é relevante, além de que essa instituição é a maior empregadora do Serviço Social, conforme levantamento do CFESS/CRESS (2014), quando representava 74,19\% do todo. No referido levantamento, identificou-se que as atribuições do/a assistente social perpassam a perícia em Serviço Social, acompanhamento, execução de serviços (penas alternativas), avaliação de políticas públicas, gerenciamento/acompanhamento em recursos humanos, assessoria e planejamento interno. Nesse leque, a única atividade comum a todos os estados foi o estudo social/perícia social, carro-chefe do trabalho profissional. A requisição pela atuação profissional no processo coloca o/a assistente social em posição estratégica, haja vista o contato com um conjunto de contradições que atravessa o social, capturado pelo litígio, de modo geral, desenraizado e simplificador do social.

Em vista disso, a atuação do/a assistente social como perito/a do juiz, designado/a para tal no processo, é tarefa profissional privativa, conforme previsão do Código de Ética Profissional, contudo, inserida na liturgia legal que prevê, no sistema jurídico brasileiro, o direito à defesa e ao contraditório. Essas garantias serão exercidas por meio da Defensoria Pública ou advogado/a particular da parte, havendo, ainda, a presença do Ministério Público em parte dos procedimentos.

O Ministério Público, por seu turno, possui outra conformação, tendo suas atribuições redesenhadas a partir da Constituição Federal de 1988, com a assunção da função de defesa do regime democrático, dos direitos individuais indisponíveis e sociais. Nesse contexto, a instituição manteve sua atuação na esfera judicial, sendo ainda titular da ação penal pública, porém a incrementou no âmbito extrajudicial, em especial na 
exigibilidade dos direitos humanos, tanto em matérias de direito individual quanto de difuso e coletivo. Organiza-se por meio do Ministério Público da União e dos estados, com ramos distintos. Como no caso do Poder Judiciário, possui autonomia financeira e administrativa, porém a chefia de cada esfera é escolhida pelo Poder Executivo.

A incorporação de assistentes sociais no Ministério Público deu-se, diferentemente do Poder Judiciário, a partir da Constituição Federal de 1988, mais precisamente em meados da década de 1990 e anos 2000. Em encontros bianuais realizados desde 2006, os assistentes sociais do Ministério Público têm discutido sua identidade profissional e inserção nesse novo campo sócio-ocupacional. No último levantamento realizado, em 2020, por assistentes sociais do Ministério Público do Paraná (Bremm, 2021), havia 379 assistentes sociais, em 22 estados brasileiros.

Desde os primeiros anos da atuação do Serviço Social no Ministério Público, embora a experiência da categoria no Poder Judiciário tenha sido uma referência para os contratantes, com base nas particularidades da atuação ministerial, vislumbrou-se um espaço vigoroso no âmbito do direito difuso e coletivo com vista à exigibilidade dos direitos sociais. A esse propósito, o relatório do Paraná (Bremm, 2021) situa que em 59\% (13) dos estados, assistentes sociais do MP atuam com abrangência regional e em 23\% (cinco), estadual, ou seja, há grupos técnicos que assessoram regiões ou municípios.

O mesmo levantamento demonstra que em 68\% (15) dos estados há atuação predominante em direitos difusos e coletivos, na esfera extrajudicial, e em $54,5 \%$ (12) das unidades envolve diferentes políticas públicas e segmentos credores de direitos, com desenho generalista. 0 mapeamento referenda que 100\% (22) dos estados respondentes informaram, entre as atividades, a realização de avaliações de instituições de atendimento, e 95\% (21), avaliações de políticas públicas.

Esses dados são compatíveis com os debates internos havidos na categoria profissional, destacando o potencial da atuação no âmbito das políticas públicas, tanto na percepção de promotores e procuradores de Justiça quanto dos próprios assistentes sociais, pois, 
[...] a missão do Ministério Público quanto à defesa e garantia dos direitos humanos coloca-o em relação direta com os demais atores da sociedade política, em especial, no caso do Ministério Público estadual, com referência às políticas públicas com os governos estaduais e municipais, pois são elas que materializam o direito à proteção social. Se não forem concretizadas na vida da população, os direitos não passam de intenções. Assim, a atuação ministerial está profundamente voltada para o fomento e a fiscalização das políticas públicas (Tejadas, 2012, p. 268, grifos da autora).

Nessa contextura, o trabalho de assistente social, de modo geral, se concretiza em um produto final denominado relatório de avaliação ou parecer técnico; produção textual que veicula a avaliação de instituições de atendimento, de políticas públicas ou, ainda, de situações individuais/ familiares. Tais documentos, de maneira geral, subsidiam a atuação do/a promotor/a de Justiça no âmbito extrajudicial ou, também, o ingresso da ação civil pública, quando judicializada uma contenda ou demanda social. Assim, estes "produtos" são documentos técnicos, de autoria de profissional habilitado/a frente ao conselho de categoria e, com isso, ao exercício profissional. Estas produções técnicas sofrerão o escrutínio e atenta avaliação de outros atores da esfera pública, como procuradorias municipais e estaduais, dirigentes, técnicos/as e procuradores/as de instituições de atendimento, dirigentes e assessores/as de movimentos sociais, membros de conselhos de direitos, entre outros. Assim, consubstanciam visão técnica sobre a qual o/a profissional possui responsabilidade civil e criminal.

Situados, sumariamente, o Poder Judiciário e o Ministério Público, bem como as principais atribuições do Serviço Social e a responsabilidade técnica inerente a este, o próximo item desenvolverá o contexto no qual se desenrola a proposta de “estágio de pós-graduação”.

\subsection{0 "estágio de pós-graduação" na seara da "Reforma Administrativa"}

No bojo das contrarreformas efetuadas desde o período Temer e incrementadas no governo Bolsonaro, que atacaram fortemente as bases 
da proteção ao trabalhador - a reforma sindical, a trabalhista e a lei das terceirizações - tem-se a reforma administrativa. Somando-se a estas, a Emenda Constitucional 95/2016 que manteve as políticas públicas com seus tetos congelados por 20 anos, ou seja, até 2036 .

Em diálogo com os demais movimentos de contrarreforma, importa um olhar apurado em direção ao Projeto de Lei n. 32/2020, do Poder Executivo, que "altera disposições sobre servidores, empregados públicos e organização administrativa”. Na verdade, seus antecedentes já estavam presentes na PEC Emergencial 186/2020 e na PEC 188/2019 (Pacto Federativo), nas quais transparece a satanização das despesas com os/as servidores/as públicos/as. Giza-se que tais movimentos ocorreram em meio ao estado de calamidade decretado em razão da pandemia da covid-19.

A proposta de contrarreforma administrativa é controversa e de complexa exposição neste artigo. Todavia, convém ao menos iluminar aspectos que tendem a enfraquecer o Estado brasileiro e, com isso, a somar efeitos ao desmantelamento do fundo público naquilo que diz respeito às políticas públicas sociais.

A PEC 32/2020, porém, nada traz de positivo ou inovador, porque discrimina o servidor público, porque fragiliza a sua relação com o Estado, porque destrói o pouco até aqui construído em termos de sistema do mérito, porque retira direitos e impõe limitações, porque aumenta o poder discricionário do governante, porque retira garantias dos cidadãos, porque fragiliza $o$ regime federativo, porque fere direitos e garantias individuais, e porque afronta a separação dos Poderes (Santos, 2020, p. 56).

Para Santos (2020), a PEC apresenta enormes fragilidades conceituais, haja vista que se associa às demais reformas na direção da diminuição do Estado. Nesse contexto, Oreiro (2020, p. 34-35, grifos nossos) sintetiza as mudanças trazidas pela PEC:

(i) criar novos vínculos e meios de acesso ao serviço público; (ii) facilitar a entrada de pessoas do setor privado em cargos de liderança; (iii) retirar direitos constitucionais dos servidores públicos; (iv) modificar a gestão 
de pessoal, carreiras, política remuneratória; (v) flexibilizar ou eliminar a estabilidade do servidor público; (vi) dar poder quase absoluto ao Presidente da República na definição da organização de cargos públicos e suas atribuições; (vii) reduzir a capacidade de atuação e intervenção estatal; (viii) transformar empresas públicas em empresas privadas, no tocante à orientação de suas atividades; (ix) destituir o Legislativo de prerrogativas de decidir sobre os aspectos da administração pública; (x) destituir os chefes de executivo dos Estados e Municípios da função de gerir a administração pública sob sua responsabilidade.

Evidentemente, a contrarreforma administrativa é apresentada em meio a um ambiente político, cultural, ideológico e econômico desfavorável à classe trabalhadora, a qual vem se gestando paulatinamente nas instituições do Sociojurídico e, aqui, especificamente, no Poder Judiciário e no Ministério Público. Nesse processo, evidenciam-se movimentos no sentido da ampliação das formas precarizadas de contratação de trabalhadores nessas instituições, em especial das terceirizações para serviços de vigilância, higienização e motoristas, bem como das contratações de cargos em comissão para atividades antes providas por servidores/as de carreira, como as assessorias jurídicas, estendendo-se a outras áreas do conhecimento.

O movimento que se gesta nas entranhas do Estado brasileiro não é desconectado daquilo que ocorre no capitalismo mundial. Antunes (2020) ensina que o capital busca incessantemente a sua expansão e autovalorização, o que resulta em grande potencial de destrutividade. Nesse movimento, o próprio labor é modulado para a finalidade da expansão e reprodução do capital. O autor destaca que, especialmente a partir das crises de 1968-1973 e 2008-2009, esse movimento foi intensificado com a produção de fenômenos relacionados a "ritmos estonteantes de corrosão do trabalho; destruição ilimitada da natureza; degradação do mundo rural, convertido em agrobusiness em zona de extrativismos predatórios; segregação urbana e social, etc." (Antunes, 2020, n.p.).

Os efeitos deletérios da crise do capital, associados ao contexto da pandemia da covid-19, relacionam-se a taxas elevadíssimas de 
desemprego, ao fortalecimento da divisão sociocultural do trabalho que penaliza de forma contundente as trabalhadoras negras (Antunes, 2020). No Brasil, calculam-se 14 milhões de desempregados, o que, associado a uma política econômica recessiva, trará consequências para o tecido social. Assistentes sociais não escapam a essa dura realidade, haja vista a desidratação das políticas sociais públicas, fonte majoritária de emprego destes/as. No mesmo contexto, provenientes de famílias trabalhadoras, na sua maioria, possivelmente os/as assistentes sociais vivem a decrepitude das condições de reprodução da própria força de trabalho no seio de seus grupos de convívio e pertencimento.

Evidentemente, tem-se um contingente de assistentes sociais recém-graduados/as ou desempregados/as, sem trabalho. Desse modo, as recentes proposições de "estágio de pós-graduação", muito provavelmente, encontrarão eco na categoria profissional. No dizer de Antunes (2020, n.p., grifos nossos), "terceirização, informalidade e flexibilidade se tornaram partes inseparáveis do léxico de empresa corporativa”. Nesse caso, o Poder Judiciário e o Ministério Público se aproximam, por meio das recentes regulamentações do "estágio de pós-graduação", do paradigma em curso da empresa corporativa, possivelmente, flexibilizando o mandato constitucional de ingresso no serviço público por meio do concurso público.

Em sumária pesquisa junto às unidades do Ministério Público, identificaram-se editais abertos para fins de contratação de "estagiário de pós-graduação” em Ceará, Goiás, Santa Catarina e São Paulo para o Serviço Social, exclusivamente, ou também para outras áreas. A remuneração prevista nas normativas varia de $R \$ 1.400,00$ a $R \$ 2.200,00$, além de auxílio-transporte e carga horária de cinco a seis horas diárias, pelo período de até dois anos, com previsão de requisitos e de cotas raciais e para pessoa com deficiência. Alguns editais preveem a realização de processo seletivo com prova, não designam as atribuições de "estagiários de pós-graduação" em Serviço Social e sinalizam que a pós-graduação deva ter carga horária mínima de 360 horas (Ceará, 2020; Goiás, 2021; Santa Catarina, 2021; São Paulo, 2021). Ainda, algumas unidades estaduais reformularam normativas já existentes sobre estágios, agregando a 
modalidade de "pós-graduação", caso do Rio Grande do Sul (2021), Paraná (2016) e Paraíba (2020).

Nos tribunais de Justiça, tem-se conhecimento de normativa a respeito no Tribunal de Justiça da Bahia e de Minas Gerais. Em Minas Gerais, identificou-se processo de inscrição, em 2019, para o Programa de Atenção Integral ao Paciente Judiciário, com vagas para Direito, Psicologia e Serviço Social. No caso da Bahia, conforme decreto Judiciário n. 790 , de 5/11/2020, entre as 100 vagas para diversas áreas constam 15 para graduados/as em "assistência social".

Cabe destacar que há incompreensão por parte daqueles/as que formulam tais Editais, demonstrando não haver a participação de profissionais assistentes sociais, uma vez que a política social de assistência social é confundida com a profissão de Serviço Social, como na normativa do Tribunal da Bahia.

Nota-se, então, no contexto aqui descrito, que a gênese dessa proposição se dá no âmbito do trabalho precarizado, uberizado, superexplorado, no mundo da indústria 4.0, do 5G, da inteligência artificial, e não na formação profissional. 0 que esse movimento do real revela? Como essa proposição/realidade repercute no processo formativo do Serviço Social, profissão que adentrou na formação em pós-graduação com destaque no cenário das ciências sociais aplicadas no Brasil? O que é exatamente o "estágio de pós-graduação" e no que se diferencia do exercício profissional? Sem a pretensão de responder definitivamente a tais questões, a seguir se incursiona em alguns tensionamentos sobre a temática.

\section{2. "Estágio de pós-graduação" no ensino superior: tensionamentos entre aprendizagem e exercício profissional}

Situados os determinantes que configuram a nova morfologia do trabalho (Antunes, 1999), ou seja, das formas de ser do trabalho e da classe trabalhadora em tempos de precarização estrutural deste, na crise 
mundial do capital, sob a hegemonia ultraneoliberal, importa adentrar nos elementos intrínsecos da formação no âmbito do ensino superior.

Nas particularidades do Serviço Social, destaca-se o acúmulo da categoria na elaboração das Diretrizes Curriculares da Associação Brasileira de Ensino e Pesquisa em Serviço Social — ABEPSS (1997) para os cursos de graduação. Tais diretrizes expressam, entre outros documentos, um projeto de formação profissional pautado no rigoroso trato teórico-metodológico, ético-político e técnico-operativo da profissão e coadunam com a Lei n. 8.662/1993 e o código de ética de assistentes sociais de 1993.

Giza-se que as instituições de ensino superior, públicas ou privadas, estão afetas ao Sistema Federal de Ensino, conforme previsão da Lei de Diretrizes e Bases da Educação. Na referida lei é considerada pós-graduação: “[...] programas de mestrado e doutorado, cursos de especialização, aperfeiçoamento e outros, abertos a candidatos/as diplomados/as em cursos de graduação e que atendam às exigências das instituições de ensino" (Brasil, 1996).

Para perscrutar a temática do "estágio de pós-graduação" é necessário, minimamente, situar a estrutura da pós-graduação no Brasil quanto às possibilidades existentes (especialização, mestrado e doutorado), distinguir o estágio docente na pós-graduação, bem como trazer a normativa brasileira sobre o estágio. Os cursos de pós-graduação stricto sensu estão definidos pela Resolução n. 7, de 11 de dezembro de 2017, da Câmara de Educação Superior do Conselho Nacional de Educação, sendo assim constituídos:

[...] os cursos de mestrado e doutorado regulares, pertencentes ao Sistema Nacional de Pós-Graduação, avaliados pela Coordenação de Aperfeiçoamento de Pessoal de Nível Superior (Capes), submetidos à deliberação pela Câmara de Educação Superior do Conselho Nacional de Educação (CES/CNE) e homologados pelo Ministro da Educação (Brasil; CNE/MEC; CAPES, 2017).

O Parecer n. 977, de 3 de dezembro de 1965, por seu turno, que trata do marco conceitual e regulatório da pós-graduação brasileira, define 
a pós-graduação lato sensu como "todo e qualquer curso que segue a graduação [...]. São cursos destinados ao treinamento nas partes de que se compõe um ramo profissional ou científico" (Brasil; CES, 1965). Desse modo, as especializações distinguem-se em abrangência e nos objetivos, pois menos amplas que mestrados e doutorados. Nos termos do referido parecer, "cursos pós-graduados de especialização ou aperfeiçoamento podem ser eventuais, ao passo que a pós-graduação em sentido próprio é parte integrante do complexo universitário, necessária à realização de fins essenciais da universidade" (Brasil; CES, 1965).

O Plano Nacional de Educação (PNE), Lei n. 13.005/2014, por seu turno, aborda, nas metas 13 e 14, a ampliação da proporção de mestres e doutores na educação superior, bem como a elevação gradual das matrículas para esses níveis de pós-graduação. Na meta 16, trata da formação em pós-graduação de professores/as da educação básica. O foco do PNE nas suas estratégias é a pós-graduação stricto sensu, sempre associada ao fomento da pesquisa, desenvolvimento tecnológico do país e suporte à educação básica.

Nesse debate, é ainda necessário observar o texto da Lei n. 11.788, de 25 de setembro de 2008 , que dispõe sobre o estágio, conceituado como:

Art. $1^{\circ}$ Estágio é ato educativo escolar supervisionado, desenvolvido no ambiente de trabalho, que visa à preparação para o trabalho produtivo de educandos que estejam freqüentando o ensino regular em instituições de educação superior, de educação profissional, de ensino médio, da educação especial e dos anos finais do ensino fundamental, na modalidade profissional da educação de jovens e adultos (Brasil, 2008).

Aponta a legislação que o estágio compõe o projeto pedagógico do curso, supervisionado pela instituição de ensino e pela parte concedente, que pode recorrer a instituições de integração públicas e privadas, desde que obedecendo às normas gerais de licitação, no caso das instituições públicas. A legislação de estágio é genérica, portanto, não trata sobre eventual "estágio de pós-graduação". 
É importante explicitar que "estágio de pós-graduação" se distingue do Estágio de Docência, no âmbito dos cursos de mestrado e doutorado, o que exige supervisão acadêmica; faz a mediação entre pós-graduação e graduação/ensino médio, compondo uma atividade formativa para os/as mestrandos/as e doutorandos/as. O Estágio de Docência está regulamentado na portaria MEC/CAPES n. 76/2010, de 14 de abril de 2010, que prevê:

Art. 18. O estágio de docência é parte integrante da formação do pós-graduando, objetivando a preparação para a docência, e a qualificação do ensino de graduação sendo obrigatório para todos os bolsistas do Programa de Demanda Social, obedecendo aos seguintes critérios:

I - para o programa que possuir os dois níveis, mestrado e doutorado, a obrigatoriedade ficará restrita ao doutorado;

II - para o programa que possuir apenas o nível de mestrado, a obrigatoriedade do estágio docência será transferida para o mestrado;

[...] V — a duração mínima do estágio de docência será de um semestre para o mestrado e dois semestres para o doutorado e a duração máxima para o mestrado será de dois semestres e três semestres para o doutorado; [...] VIII — as atividades do estágio de docência deverão ser compatíveis com a área de pesquisa do programa de pós-graduação realizado pelo pós-graduando;

[...] X - a carga horária máxima do estágio de docência será de 4 horas semanais (Brasil; CES/CAPES, 2010).

Nesse contexto, é uma atividade curricular obrigatória para os/as bolsistas (demanda social) CAPES e opcional para aos demais pós-graduandos stricto sensu, devendo possibilitar ao/à estudante a experiência de aprendizagem relacionada à docência, sob a supervisão de professor em disciplina de pós-graduação stricto sensu, em cursos de lato sensu e de qualificação profissional, em graduação, ensino médio e cursos técnicos, conforme parcerias estabelecidas entre as instituições de ensino formadoras. A participação do/a estudante de pós-graduação não cria vínculo empregatício com a instituição formadora. 
Com base nas descrições de atividades e demais elementos, é possível afirmar que o "estágio na pós-graduação" tratado neste artigo em nada se assemelha ao Estágio de Docência, tampouco guarda relação com a Lei que regulamenta o estágio, visto que não se têm notícias de instituições de ensino superior, com mestrado e doutorado em Serviço Social, com previsão de estágio, exceto o docente. No campo do lato sensu, as formações são muito fluidas em termos de conteúdos e, até mesmo, de carga horária, havendo diversas temáticas em questão, porém, também, não se tem conhecimento de previsão de estágio naquelas que tratam de temáticas atinentes ao Serviço Social no Sistema de Justiça. Giza-se que no mercado em expansão das especializações, inclusive o trabalho de conclusão de curso vem sendo abdicado para tornar a formação mais célere e menos onerosa ao estudante.

No âmbito da categoria profissional, somente o estágio de graduação no Serviço Social tem amplo debate, destacando-se a Política Nacional de Estágio (2009) que apresenta orientações para essa prática educativa na graduação. A supervisão direta de estágios na graduação está regulamentada pelo Conselho Federal de Serviço Social por meio da Resolução CFESS 533/2008, a qual apresenta a exigência de profissional no campo de estágio e na academia, ou seja, supervisão direta no espaço sócio-ocupacional e na unidade de ensino.

A análise dos editais em curso, em 2021, permite inferir que o chamado "estágio de pós-graduação", nas unidades do Ministério Público e nos Tribunais de Justiça mencionados, aparentemente, não encontra amparo nos marcos normativos vigentes. Inclusive, porque parte do empregador e não das unidades de ensino superior nasce no contexto de enxugamento do Estado e da precarização do trabalho, portanto como uma forma de contrato precarizado. Todavia, indaga-se quanto ao caminho a seguir: 0 debate deve estar situado na dimensão do trabalho profissional, o que levaria à exigência de registro profissional; situar tais "estágios na pós-graduação" como trabalho, com registro no conselho, resolveria o impasse?

Arrisca-se ponderar que essa medida isolada não resolveria tal dilema. A esse propósito, em 22/8/2021, o Conselho Pleno do CFESS acolheu o 
parecer jurídico n. 07/2021-E, que reitera posição emitida em 2018, sobre a exigência de registro profissional ao "estagiário de pós-graduação" considerando se tratar de exercício profissional. Não obstante a posição do CFESS, nesse momento ainda inicial dos debates, muito provavelmente a estratégia de exigência de registro profissional reafirme que é possível o exercício profissional por meio desse contrato travestido de estágio. Pondera-se, então, a possibilidade de perseguir outros caminhos, como meio de lidar com essa armadilha — não é estágio, mas é estágio; não é trabalho, mas é trabalho: é um "trabalho" disfarçado de "estágio".

A situação é complexa e contraditória e demanda a atuação conjunta de diversas organizações, tanto as que regulam a atuação profissional e o ensino e pesquisa em Serviço Social quanto as de defesa do/a trabalhador/a. Algumas das contradições parecem se situar na exigência de registro profissional e nos limites da responsabilidade do profissional estagiário e do contratante. A exigência de registro sugere que esse profissional possa ter autoria de documentos técnicos. Tais documentos, como referido, situam-se em processo judicial e/ou expedientes administrativos, envolvendo interesses múltiplos de pessoas e instituições, podendo com certa facilidade ser questionados, do ponto de vista formal na atuação das instituições implicadas, quanto ao fato de serem de autoria/assinados de/por "profissional/estagiário". Além disso, cria-se um ambiente de constrangimento ético ao profissional/estudante, pois não seria um exercício ilegal na profissão, então qual o limite da responsabilização profissional e do empregador?

Sabe-se que, aqui, não se deve tratar o estudante da pós-graduação como se fosse estudante da graduação, pois o primeiro tem uma condição diferente que é ser graduado. Ser facultado o registro do Conselho não significa que o Conselho não esteja atento à questão de ele ser profissional, mas o reconhecimento de que, naquele espaço, o estudante é considerado estagiário e não profissional.

Ainda, sendo "estágio de pós-graduação", as atividades devem ser subsidiárias ao trabalho profissional, nunca substitutivas do assistente social em exercício, desse modo o/a estagiário/a não poderá realizar e 
assinar pareceres sozinho/a, em substituição ao profissional. A responsabilidade pelo trabalho técnico deve sempre ser do profissional contratado como assistente social, preferencialmente por meio do concurso público. Também se levanta a questão da supervisão de campo, qual a habilitação necessária para esta função: níveis superiores de pós-graduação em relação ao/à "estagiário/a"?

Sem desconhecer a necessidade de aprofundar os diferentes ângulos dessa questão, especialmente as polêmicas e as armadilhas em torno do "estágio de pós-graduação" no campo da formação - o que não é possível realizar aqui, dados os limites deste texto - interessa trazer preliminarmente as contribuições do pensamento crítico, evidenciando a atualidade e a urgência desse debate. Do mesmo modo, incidir na dimensão política e de aprendizagem, fazendo-se necessário ampliar o debate em meio à ABEPSS, ao conjunto CFESS/CRESS e às associações profissionais e sindicais dos trabalhadores da área sociojurídica.

\section{À guisa de conclusão: um convite ao debate!}

As reflexões aqui expostas estão longe de esgotar a complexidade das armadilhas da Reforma Administrativa e da precarização estrutural do trabalho em tempos de crise mundial do capital, as quais se encontram na base da emergência da proposta do "estágio na pós-graduação", reconfigurada e agravada por novas determinações do desemprego e da desigualdade social.

O Judiciário e o Ministério Público, tensionados pela conjuntura apresentada, recorrem a essa medida, que nasce do ambiente laboral e não da formação, indicando se tratar de procedimento que, na verdade, precariza o trabalho de diversas categorias, entre elas o Serviço Social. Contraditoriamente, esse estratagema emerge das instituições que deveriam assegurar as bases do Estado de Direito.

A questão apresenta repercussões e gravidade que implicam desafios éticos, de regulamentação da profissão e, principalmente, no campo 
da formação. Como, preliminarmente, se constitui em uma forma de precarização do trabalho e de evitação da contratação de servidores para o quadro efetivo, é preciso constituir estratégias de resistência. Vislumbram-se três eixos de resistência, envolvendo as seguintes entidades e instâncias: a) conjunto CFESS/CRESS, no diálogo constante com profissionais da área sociojurídica, reafirmando seu papel de fiscalização do exercício profissional e da supervisão direta de estágios nos moldes da Resolução 533; b) ABEPSS e as entidades vinculadas à formação em Serviço Social, em diálogo constante com a direção de universidades e programas de pós-graduação, ampliando o debate em torno de projeto de formação continuada; c) sindicatos dos trabalhadores do Ministério Público e Tribunal de Justiça.

Mesmo que o "estágio de pós-graduação" venha a compor projetos pedagógicos de determinados cursos, sobre o que não se tem conhecimento, é necessário assegurar requisitos mínimos aos processos de formação, como a existência de supervisor acadêmico e de campo, entre outros elementos didático-pedagógicos. Ademais, não se vislumbrou na pesquisa realizada regulamentação para esse tipo de estágio, já que sua previsão, no ensino superior, comumente, dá-se no âmbito da graduação.

Por fim, e não menos importante, assinala-se que os processos de trabalho no Ministério Público e no Poder Judiciário situam-se no campo formal das lides no âmbito judicial ou na disputa de distintos interesses no extrajudicial. Dessa forma, pela gravidade e amplitude de seus efeitos na sociedade, tais processos interventivos exigem a plena habilitação profissional e o processo seletivo para esse fim específico, no âmbito do serviço público. Por isso, reafirmam-se a defesa de concursos públicos e uma política de Estado para o serviço público em todas as esferas. A não prestação dos serviços ministeriais ou jurisdicionais com o desvelo requerido pode representar lesas irreparáveis à sociedade, não tendo os/as estudantes, em qualquer tipo de estágio, responsabilidades sobre processos de trabalho finalísticos, visto se tratar de momento de aprendizagem e de estudos práticos. 


\section{Referências}

ABEPSS. Política Nacional de Estágio. 2010. Disponível em: http://www.abepss.org.br/ politica-nacional-de-estagio-da-abepss-11. Acesso em: 2 set. 2021.

ABESS/CEDEPSS. Diretrizes gerais para o curso de Serviço Social (com base no currículo mínimo aprovado em assembleia geral extraordinária de 8 de novembro de 1996). Cadernos ABESS, São Paulo: Cortez, n. 7: Formação profissional: trajetórias e desafios, edição especial, 1997.

ANTUNES, Ricardo. Os sentidos do trabalho: ensaios sobre a afirmação e negação do trabalho. São Paulo: Boitempo, 1999.

ANTUNES, Ricardo. Coronavírus: o trabalho sob fogo cruzado. São Paulo: Boitempo, 2020.

BAHIA. Poder Judiciário. Decreto Judiciário n. 795, de 5 de novembro de 2020. Salvador: Tribunal de Justiça do Estado da Bahia, 2020.

BORGIANNI, Elisabete. Para entender o Serviço Social na área sociojurídica. Serviço Social \& Sociedade, São Paulo: Cortez, n. 115, p. 407-442, jul./set. 2013. Disponível em: https://www.scielo.br/j/sssoc/a/m7fYNtwTngwKyg3N7DWB8yS/?format=pdf. Acesso em: 24 ago. 2021.

BRASIL. Lei n. 9.394, de 20 de dezembro de 1996. Estabelece as diretrizes e bases da educação nacional. Brasília, 1996. Disponível em: https://www.planalto.gov.br/ccivil_03/ Leis/L9394.htm. Acesso em: 29 ago. 2021.

BRASIL. Lei n. 11.788, de 25 de setembro de 2008. Lei do Estágio. Brasília, 2008. Disponível em http://conteudo.cvm.gov.br/export/sites/cvm/menu/acesso_informacao/servidores/ estagios/3-LEGISLACAO-DE-ESTAGIO.pdf. Acesso em: 26 ago. 2021.

BRASIL. Lei n. 13.005/2014. Aprova o Plano Nacional de Educação - PNE e dá outras providências. Brasília, 2014. Disponível em: http://pne.mec.gov.br/18-planos-subnacionaisde-educacao/543-plano-nacional-de-educacao-lei-n-13-005-2014. Acesso em: 29 ago. 2021.

BRASIL; CES. Parecer n. 977, de 3 de dezembro de 1965. Marco conceitual e regulatório da pós-graduação brasileira. Brasília, 1965.

BRASIL; CES/CAPES. Portaria n. 76, de 14 de abril de 2010. Brasília, 2010. Disponível em: http://www.sr2.uerj.br/dcarh/download/Portaria_076_RegulamentoDS.pdf. Acesso em: 27 ago. 2021.

BRASIL; CNE/MEC; CAPES. Catálogo de normas e atos administrativos. Resolução n. 7, de 11 de dezembro de 2017. Estabelece normas para o funcionamento de cursos de pós-graduação stricto sensu. Brasília, 2017. 
BREMM, Andressa et al. Relatório final. In: ENCONTRO NACIONAL DO SERVIÇO SOCIAL NO MINISTÉRIO PÚBLICO, 8, 2021. Curitiba. Anais [...]. Curitiba: Ministério Público do Paraná, 2021. I Evento virtual.

CEARÁ. Ministério Público do Estado do Ceará. Ato normativo n. 076/2020. Institui, no âmbito do Ministério Público do Estado do Ceará, o estágio para estudantes em nível de pós-graduação e dá outras providências. Fortaleza, 2020.

CFESS. Resolução n. 533, de 29 de setembro de 2008. Regulamenta a supervisão direta no estágio no Serviço Social. Brasília, 2008. Disponível em: http://www.cfess.org.br/arquivos/ Resoluca0533.pdf. Acesso em: 2 set. 2021.

CFESS. Atuação de assistentes sociais no sociojurídico: subsídios para reflexão. Brasília, 2014. Disponível em: http://www.cfess.org.br/arquivos/CFESSsubsidios_sociojuridico2014. pdf. Acesso em: 2 set. 2021.

CFESS. Parecer jurídico n. 07/2021-E, de 26/04/2021, acatada em reunião do conselho pleno realizada em 22 ago. 2021.

FÁVERO, Eunice. Serviço Social no sociojurídico: requisições conservadoras e resistências na defesa de direitos. Serviço Social @ Sociedade, São Paulo: Cortez, n. 131, p. 51-74, jan./abr. 2018.

GOIÁS. Ministério Público do Estado de Goiás. Edital de processo seletivo para estágio n 01/2021. Goiânia, 2021.

OREIRO, José Luis. A PEC 32 da reforma administrativa: reformar o serviço público para acabar com o Estado do Bem-Estar Social e implantar o Estado neoliberal. Out. 2020. Disponível em: https:/www.anfip.org.br/wp-content/uploads/2020/10/RA-NT-JOSE-LUISOREIRO-1.pdf. Acesso em: 24 ago. 2021.

PARAÍBA. Ministério Público do Estado da Paraíba. Resolução CPJ n. 036/2020. Dispõe sobre seleção de estagiários profissionais no âmbito do Ministério Público da Paraíba. João Pessoa, 2020.

PARANÁ. Ministério Público do Estado do Paraná. Resolução n. 4171, de 18 de agosto de 2016, que aprova o regulamento de estágios no âmbito do Ministério Público do Estado do Paraná. Disponível em https://escolasuperior.mppr.mp.br/arquivos/File/Divisao_Estagio/ Legislacao_Estagio/41712016.pdf. Acesso em: 30 ago. 2021.

RIO GRANDE DO SUL. Ministério Público do Estado do Rio Grande do Sul. Provimento n. 31/2021. Institui o estágio de pós-graduação no âmbito do Ministério Público do Rio Grande do Sul. Porto Alegre, 2021.

SANTA CATARINA. Ministério Público de Santa Catarina. Edital n. 98/2021. Estágio de pós-graduação em Serviço Social. Florianópolis, 2021. 
SANTOS, Luiz Alberto dos. A Reforma Administrativa (PEC n. 32, de 2020): análise de seu conteúdo e constitucionalidade. Diálogo Institucional: assessoria e análise de políticas públicas, set. 2020 .

SÃO PAULO. Ministério Público do Estado de São Paulo. Abertas inscrições para programa de estágio do MPSP: podem concorrer alunos de ensino médio, de graduação e pós-graduação. São Paulo, 27 ago. 2021. Disponível em: http://www.mpsp.mp.br/portal/page/ portal/noticias/noticia?id_noticia=24977922\&id_grupo=118. Acesso em: 30 ago. 2021.

TEJADAS, Silvia da Silva. O direito humano à proteção social e sua exigibilidade: um estudo a partir do Ministério Público. Curitiba: Juruá, 2012.

TJMG seleciona estagiários de pós-graduação de direito e psicologia. Estado de Minas, Belo Horizonte, 9 out. 2019. Emprego. Disponível em: https:/www.em.com.br/app/ noticia/emprego/2019/10/09/interna_emprego,1091354/tjmg-seleciona-estagiarios-depos-graduacao-de-direito-e-psicologia.shtml. Acesso em: 2 set. 2020.

\section{Sobre os autores}

Silvia Tejadas - Assistente social do Ministério Público. Mestre e doutora em Serviço Social.

E-mail: silviastejadas@gmail.com

Maria Liduína de Oliveira e Silva - Coordenadora do Programa de Pós-Graduação em Serviço Social e Políticas Sociais, docente do curso de Serviço Social. Coordenadora Nacional de Pós-Graduação da ABEPSS, gestão 2021-2022.

E-mail: liduoliveira90@gmail.com

RodRIgo JosÉ TeIXEIRA - Assistente social, mestre e doutor em Serviço Social, professor adjunto no curso de Serviço Social. Presidente da ABEPSS, gestão 20212022.

E-mail: rodrigosersocial@gmail.com 